\title{
Impacto do Hipotireoidismo entre Mulheres Climatéricas
}

Autor: Adriano Bueno Tavares

Orientador: Prof. Dr. Marcos Dias de Moura

Dissertação apresentada ao Departamento de Ginecologia e Obstetrícia da Faculdade de Medicina de Ribeirão Preto da Universidade de São Paulo para a obtenção do título de Mestre em Tocoginecologia, em 09 de abril de 1999.

O hipotireoidismo constitui uma doença de manifestação insidiosa, cujo diagnóstico clínico é de grande dificuldade, sobretudo em mulheres no período climatérico, quando ocorre sobreposição de seu espectro clínico com aquele apresentado pela insuficiência ovariana, podendo ocasionar uma prevalência subestimada deste problema nesta população. A falta de diagnóstico desta desordem tireoideana ocasiona um aumento do risco cardiovascular, piora da função cognitiva e da qualidade de vida. Com o objetivo de avaliar o impacto do hipotireoidismo em mulheres no período climatérico, realizou-se um estudo clínico transversal de modo a poder estimar a prevalência desta doença entre mulheres que demandavam assistência de um serviço de climatério, assim como caracterizar o risco destas mulheres em apresentar a forma declarada da doença. Avaliou-se a função tireoideana de 100 mulheres entre 40 e 65 anos, através da dosagem de TSH e tiroxina (T4 livre) séricos, além da presença de anticorpos contra o tecido tireoideano. Identificou-se uma prevalência de 5\% de casos de hipotireoidismo, além disto, verificou-se que 14\% das mulheres apresentavam-se com risco elevado para o desenvolvimento da forma declarada da doença. Os resultados evidenciaram que esta população específica apresenta um risco significativo de ocorrência de hipotireoidismo, o que poderia justificar a introdução de métodos para seu rastreamento, como a dosagem de $\mathrm{TSH}$ sérico, na propedêutica de rotina do climatério.

Palavras-chave: Menopausa. Hipotireoidismo.

RBC0 $21(9): 560-561,1999$

Resumo de Tese

\section{Fatores Prognósticos em Câncer de Mama em Mulheres Pré e Pós-Menopausa}

Autor: José Ricardo Paciência Rodrigues

Orientador: Prof. Dr. Paulo Traiman

Tese Apresentada no Curso de Pós-Graduação em Ginecologia e Obstetrícia, Área de Concentração em Ginecologia, da Faculdade de Medicina de Botucatu - UNESP, para obtenção do título de Doutor em 19 de dezembro de 1998.

A incidência crescente, a heterogeneidade e a taxa elevada de mortalidade do câncer de mama, têm estimulado pesquisas com o objetivo de se identificar fatores que facilitam a compreensão do comportamento biológico desta neoplasia. Estes fatores podem ser classificados em prognósticos ou preditivos. Neste estudo, foram avaliados fatores anatomopatológicos (tamanho do tumor, comprometimento de linfonodos axilares (LA) e graduação histológica do tumor) e fatores biológicos (expressão do receptor de estrogênio (RE) e expressão do oncogene c-erb B-2.). As pacientes foram divididas em 2 grupos: grupo A; 50 pacientes com carcinoma ductal invasivo com até 40 anos de idade e grupo B: 50 pacientes com carcinoma ductal invasivo com mais de 60 anos de idade. Entre os fatores anatomopatológicos estudados, o tamanho do tumor foi dividido, de acordo com o maior diâmetro, em 3 subgrupos; T1 < 2cm, T2 de 2 a $5 \mathrm{~cm}$ e T3 $>5 \mathrm{~cm}$. O comprometimento de LA em 3 subgrupos: L1= ausência de metástase, $\mathrm{L} 2=$ metástases em 1 a 3 linfonodos e L3 = metástases em 4 ou mais linfonodos e a graduação histológica foi em 3 subgrupos, dependendo do escore obtido: G1= escores 3-5, G2= escores 6-7 e G3= escores 8-9. Os fatores biológicos foram analisados através de técnica imuno-histoquímica utilizando-se o complexo avidina-biotina-peroxidase (ABC) com o auxílio do método de recuperação antigênica pelo forno de microondas e os resultados expressos como positivo e negativo para o RE e proteína do oncogene c-erbB-2. A análise estatística foi realizada através do teste de Goodman para contraste entre e dentro de 2 populações multinomiais independentes. O teste do Qui-quadrado e o teste exato de Fisher foram utilizados para avaliar a associação entre o tamanho do tumor, LA, graduação histológica, RE e c-erbB-2 nos grupos A e B, separadamente. A idade das pacientes nos grupos A e B variou de 25 a 40 anos (média de 35 anos) e 60 a 85 anos( média de 68 anos) respectivamente. No grupo A, o tamanho do tumor variou de 0,7 a $8,0 \mathrm{~cm}$ (média de $2,9 \mathrm{~cm}$ ) e no grupo B a variação foi de 0,8 a $9,0 \mathrm{~cm}$ (média de $3,1 \mathrm{~cm}$ ). Foram examinados, em média, nos grupos A e B, respectivamente, 19,9 LA e 22,1 LA. A média de LA comprometidos por metástases foi de 4,7 LA e 4,4 LA, respectivamente, nos grupos A e B. Os resultados não mostraram diferença, estatisticamente significante, entre os 2 grupos em relação ao tamanho do tumor, LA, graduação histológica e expressão de RE nos grupos A e B. Tumores de 2 a $5 \mathrm{~cm}$ predominaram em ambos os grupos. No grupo A, a axila negativa $(52 \%$ e G3 (46\%) foram mais freqüentemente encontrados. Nos grupos A e B, positividade para expressão de RE foi predominante em relação à negatividade. A expressão do c-erbB-2 ocorreu com diferença estatisticamente significante mais freqüentemente no 
grupo A (26\%) do que no grupo B (12\%). Observou-se maior número de associação entre variáveis no grupo A do que no grupo B. Em ambos os grupos, verificou-se associação da expressão do $\mathrm{RE}$ com graduação histológica e expressão da proteína do oncogene c-erbB-
2. No grupo A, evidenciou-se também associação do tamanho do tumor com graduação histológica e presença de metástase em LA.

Palavras-chave: Mama: câncer. Menopausa.

\section{Ultra-Sonografia Transretal Contribuição ao Estadiamento do Câncer do Colo Uterino}

Autor: José Augusto Machado

Orientador: Prof. Dr. Paschoal Martini Simões

Tese de Doutorado apresentada no Instituto de Ginecologia da Universidade Federal do Rio de Janeiro - UFRJ, em 26 de novembro de 1998.

Foram examinadas pelo autor 32 pacientes com carcinoma escamoso do colo uterino no Setor de Ultrasonografia do Instituto de Ginecologia da Universidade Federal do Rio de Janeiro no período entre março de 1995 e agosto de 1998. O exame USTR realizado na fase de estadiamento clínico da patologia tinha como objetivo avaliar qualitativamente o envolvimento neoplásico parametrial e mensurar o maior diâmetro transverso do tumor. Todas as pacientes foram submetidas ao tratamento cirúrgico, o que permitiu a confrontação dos resultados USTR com os achados anatomopatológicos da peça operatória. A análise dos resultados obtidos mostram um alto grau de confiabilidade do exame USTR em determinar o comprometimento parametrial pela neoplasia. A análise estatística do método mostrou-se significativa para $\mathrm{p}<0.01$ com sensibilidade de $80 \%$ e especificidade de
95\%. O valor preditivo positivo e negativo do exame testado foi de $88 \%$ e $91 \%$ respectivamente. Na série total, foram analisadas ainda a distribuição do tamanho do tumor mensurado pelo exame USTR (maior diâmetro transverso), em que a menor e maior medida do tumor visivel foi de $11 \mathrm{~mm}$ e $28 \mathrm{~mm}$ respectivamente, em quanto que a média e moda das medidas aferidas foi de $19,9 \mathrm{~mm}$. e $18 \mathrm{~mm}$. respectivamente. Conclui-se que os sonogramas compativeis com a infiltração parametrial, caracterizado pelo padrão hipoecogênico, são raramente observados na ausência do comprometimento neoplásico. A alta especificidade do método desempenhou papel relevante em contribuição ao estadiamento clínico preciso.

Palavras-chave: Ultra-sonografia. Colo uterino: câncer. Estadiamento. Paramétrio.

\section{Estudo Descritivo da Mini-Laparoscopia em Pacientes com Algia Pélvica}

Autor: Waldir Pereira Modotte

Orientador: Prof. Dr. Rogério Dias

Dissertação de Mestrado, apresentada à Faculdade de Medicina de Botucatu - UNESP, em 28 de julho de 1999.

A algia pélvica constitui ainda nos dias de hoje um grande enigma para os clínicos. Pacientes com esse sintoma são submetidos a diferentes regimes de tratamento clínico e cirúrgico, sem sucesso. Elas geralmente são ansiosas, apresentam depressão associada e graves rupturas no campo ocupacional, social e marital. O estudo analisa variáveis como: duração do procedimento, tempo de permanência na recuperação, qualidade técnica de imagem, achados laparoscópicos, tolerância ao método anestésico sob sedação consciente, morbidade pós-operatória e aceitabilidade do procedimento cirúrgico. Foram analisadas prospectivamente 32 pacientes com algia pélvica, com idade média de 30 anos, submetidas a vídeo-minilaparoscopia. Para analisar a tolerância do método, foram aplicados dois questionários referentes ao desconforto observado durante o procedimento, um baseado nos critérios de Bordahl et al (1993) e outro segundo os critérios de Milki e Tazuke (1996). O tempo de duração médio da vídeo-minilaparoscopia foi de 19 minutos, o tempo de permanência na recuperação médio de 43 minutos, e a qualidade de imagem excelente e boa em 100\% das pacientes selecionadas. Foram encontrados os seguintes achados laparoscópicos: $36,7 \%$ de endometriose, 30\% de aderências pélvicas, $13,3 \%$ de varizes pélvicas e de normalidade. Foi observada uma baixa freqüência de manifestação dolorosa durante a anestesia local $(12,5 \%)$ e relativo desconforto $(46,9 \%)$ na realização do pneumoperitônio. Observou-se que o método apresenta tolerância muito boa e boa em $96,9 \%$, segundo os critérios de Milki e Tazuke (1996). A morbidade do método, 24 horas após o procedimento, segundo os critérios de Chung et al (1996) mostrou elevada freqüência de dor no local da incisão $(59,4 \%)$ e sonolência (43,8\%). Apenas 3,1\% referiu dor durante o procedimento, mostrando boa aceitabilidade ao método.

Palavras-chave: Algia pélvica. Minilaparoscopia. Cirurgia ambulatorial. Laparoscopia. 